\title{
An Economic Analysis on Spatial Integration of Regional Rice Markets in Sri Lanka
}

\author{
Udith K. Jayasinghe-Mudalige*
}

\begin{abstract}
This paper examines the impact of price originated in the Central Rice Market (i.e. Colombo) on the price formation in a set of geographically dispersed Regional Rice Market in Sri Lanka (i.e. Anuradhapura, Kandy, Kurunegala, Nuwara-Eliya and Pollonnaruwa). It uses the monthly retail prices of rice in these markets from January 1996 to December 2003. The outcome of the analysis suggests that prices in these markets, irrespective of the whether they are surplus or deficit markets, were highly integrated both in the short-run and long-run perspectives. It has important implications for food and agricultural policy, i.e. government interventions at the Central Market such as food imports and export bans etc. are effective in Regional Markets.
\end{abstract}

\section{Introduction}

Rice is the major staple food of Sri Lanka with a per capita consumption of about $92 \mathrm{~kg}$ per annum. Approximately 80,000 farm families and 1.8 million farmers are engaged in cultivating paddy, which occupies nearly 34 percent of the total cultivated area of the country. There are more than 6.5 million people, i.e. nearly 30 percent of the total population in the island, are either directly or indirectly involved with various activities related to the paddy industry, including production, processing, and marketing (both domestic and international trade).

Although the Central Bank of Sri Lanka (2005) reports that Sri Lanka has been able to reach the target of producing more than 95 percent of its total rice requirement in the recent past, it has been subjected to a growing debate amongst the economists, as the government in power had to import more than 5 percent of rice consumed in the country in recent years. Nevertheless, it

Senior Lecturer, Department of Agribusiness Management, Faculty of Agriculture and Plantation Management, Wayamba University of Sri Lanka, Sri Lanka. 
must be noted that there exists a political economy that heavily support both the production and marketing of paddy heavily and persistently through subsidies, for example for fertilizer, distribution of seed paddy and public investments on large to small-scale irrigation schemes covering every geographical region, certified prices and establishing marketing boards and co-operative systems for distribution etc.

The total paddy production of the country was over 3,000,000 metric tones in 2003. However, the quantities of production have been fluctuated considerably over the years and in certain years dropped significantly because of various climate changes (e.g. severe drought prevailed in the country in 1996) (Figure 1).

Figure 1: $\quad$ Performance of paddy sector in Sri Lanka



Although paddy is cultivated in all 9 provinces in Sri Lanka, the Eastern (EST), North Central (NCP) and North Western (NWP) Provinces are responsible for a majority of production with mean annual production of 544, 
463 and 344 thousand Metric Tones, respectively, covering the period 1979 to 2003 (Figure 2).

Figure 2: $\quad$ Province-wise mean annual production of paddy in Sri Lanka $(1979-2003)$

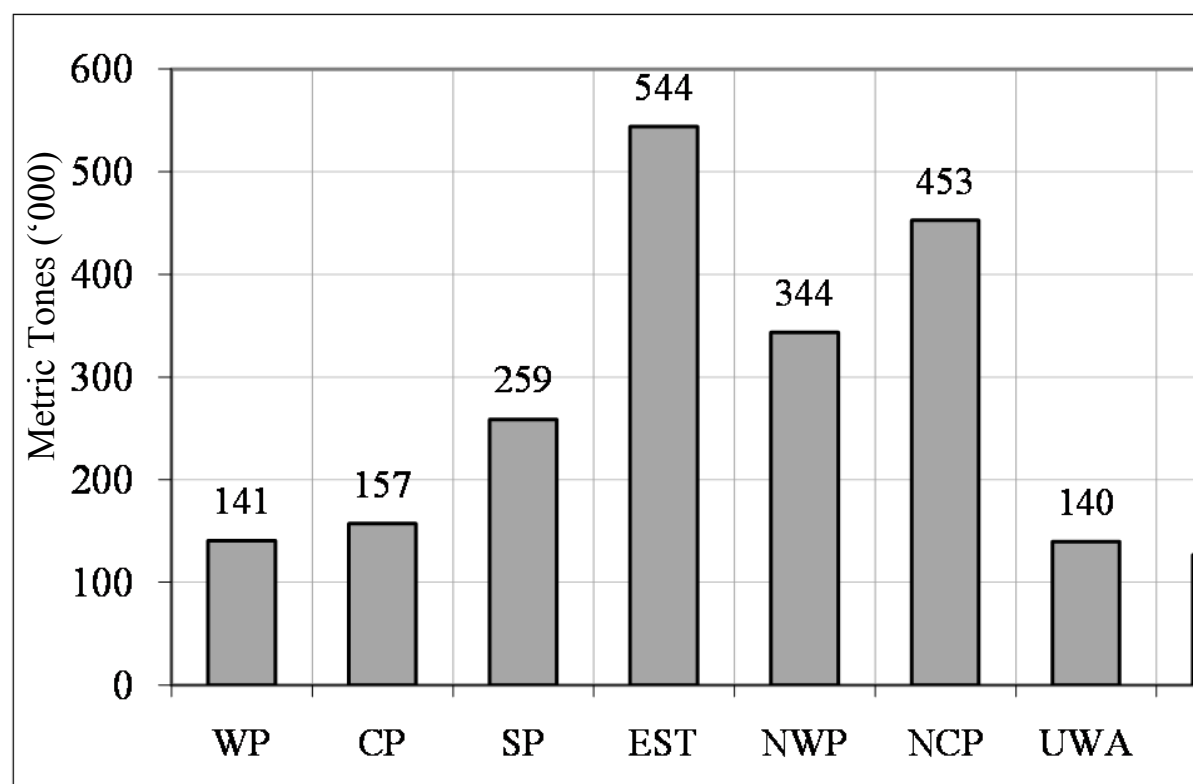

Note: $\mathrm{WP}=$ Western Province; $\mathrm{CP}=$ Central Province; $\mathrm{SP}=$ Southern Province; UWA = Uwa Province; SBP = Sabaragamuwa Province

Out of the 24 districts in Sri Lanka, only 6 districts, namely Anuradhapura (ANU) and Polonnaruwa (POL) in the Ampara (AMP) and Batticoloa (BAT) Kurunegala (KUR) and Hambantota (HAM) have produced paddy with an average of 100 thousand Metric Tones per year over the last twenty-five years. In fact, these six districts are responsible for more than 50 percent of the total annual domestic paddy production. The mean annual paddy production within this period was the lowest (i.e. less than 20,000 Metric Tones) in Colombo (COL) and Nuwara-Eliya (NUW) districts (Figure $3)$. 
Figure 3: District-wise mean annual production of paddy in Sri Lanka $(1979-2003)$

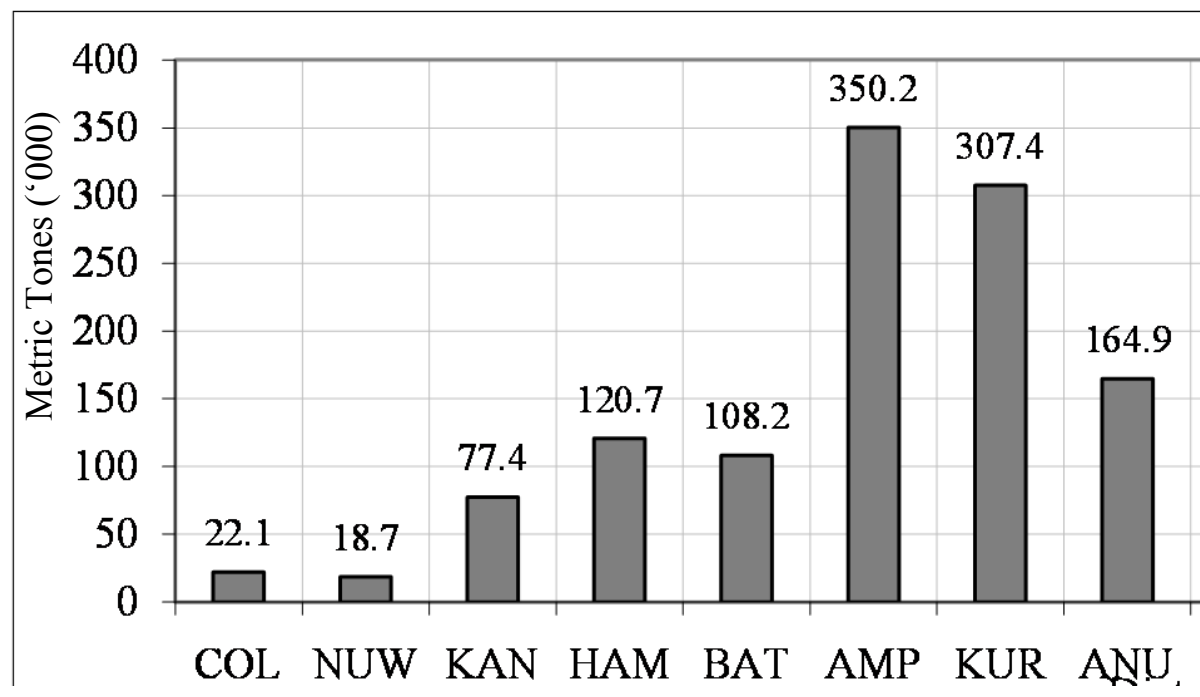

The Potential Per Capita Availability of Paddy (PPCAP) in a given geographical area can be regarded as a sensible measure to demonstrate the performance of paddy industry in Sri Lanka on a regional basis.

Figure 4 illustrates the value of PPCAP for six districts in Sri Lanka, where the PPCAP was calculated by taking the ratio between mean production of paddy of each district for the period of $1979-2003$ and the number of people in the respective district in 2003. We have assumed that the trading of paddy is fully restricted to the district where it is produced, and intra-district allocation of paddy for the people in that district is efficient. This clearly shows that some districts, for example Polonnaruwa and Anuradhapura, possesses sufficient amount of paddy (i.e. above the national average of $98 \mathrm{~kg} /$ person / year) to feed the population in that district, given that these two assumptions are satisfied. In contrary, some other districts, for example Colombo and Nuwara-Eliya and Kandy will have to engage in paddy trading with the regional markets located in the other districts in order to maintain the first condition associated with food security (i.e. availability of sufficient amount of food) for the people live in these districts as their per capita availability of food is quite below the national average of $98 \mathrm{~kg} /$ year. 
Figure 4: $\quad$ Potential per capita availability of paddy in selected districts in Sri Lanka

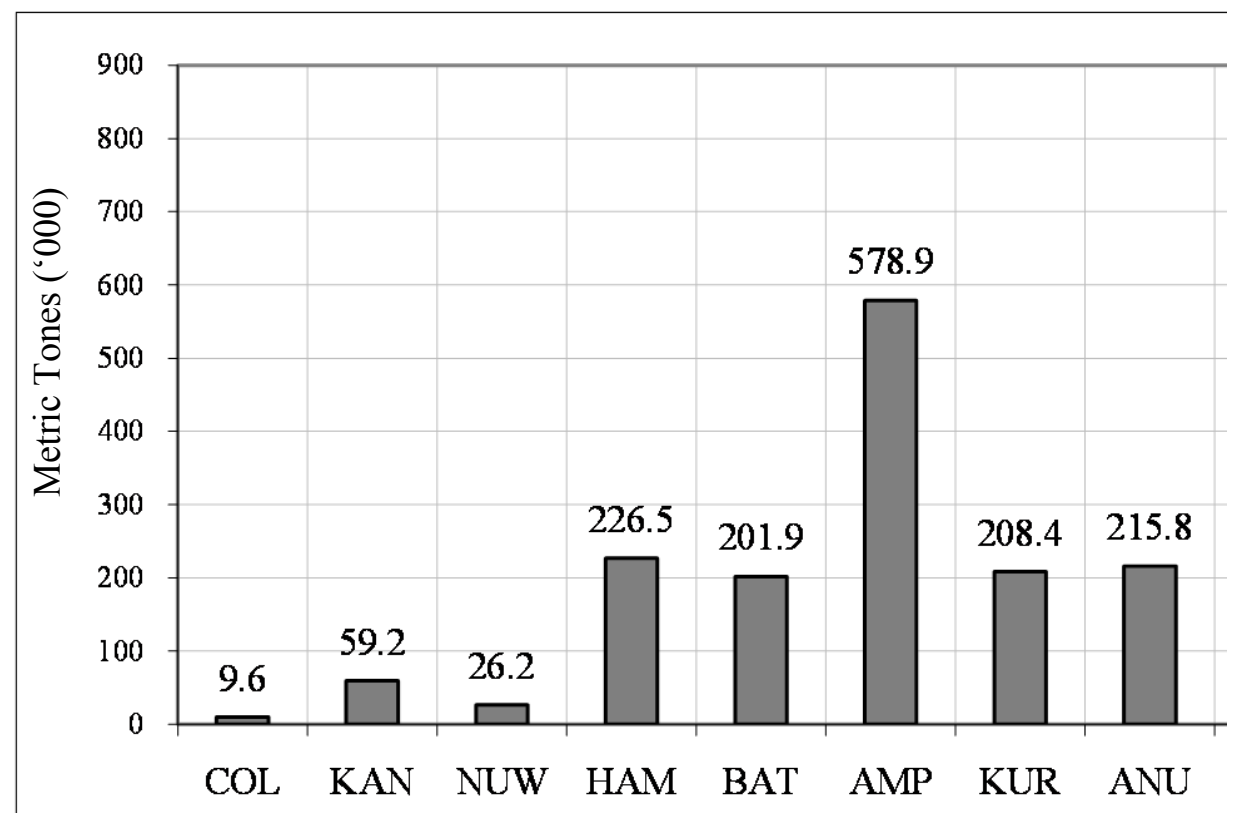

These highlight that it is of paramount importance to have an efficient regional marketing structure for paddy production and processing sectors in Sri Lanka that facilitate surplus regional markets to sell their products and those deficit markets to buy them without distortions to the price. In other words, trading markets for these products must be fully integrated so that price changes in one-market leads to an identical price response in the other. It may also be defined as a situation in which arbitrage causes prices in different markets to move together (Ravallion, 1986). On the other hand, markets that are not integrated properly may convey inaccurate price information to consumers, which may in turn distort decisions with regard to marketing and contribute to inefficient product movements. Associated with market integration is the degree of price transmission, which may have an effect on speed of traders to move food to deficit areas, especially during emergencies such as droughts, floods or pestilence.

Evidence on whether the markets are integrated or not, and if integrated, extent to which degree it occurs is therefore vital for both 
economists and policy makers to instigate appropriate programs/projects aiming food security and to formulate favourable agricultural policies. If markets were properly integrated, the effect of policy intervention in one market would be transmitted to other markets efficiently. In contrary, if the markets were segmented, each market would need to have its own policies and/or programs that involve high transaction costs, i.e. search, negotiate and verification costs involved with establishing contracts with other markets. For example, if there is a shortfall in rice albeit the rice markets of Sri Lanka are highly integrated, importing of rice to the Colombo port (Central Rice Market) would be sufficient to alleviate food shortage in other markets, since price changes resulting from increase supply in Colombo would be transmitted to regional markets and make rice trade to adjust accordingly.

The purpose of this study was, therefore, to examine empirically the extent to which degree the geographically dispersed rice markets in Sri Lanka are integrated with the focus on the impact of price of rice in the Colombo on other points in the rice trading system. There are only a few studies available to date that have examined empirically economic problems along this line: rice markets in the Mekong River Delta region in the Vietnam (Lutz et al., 2006), Bangladesh (Goletti et al., 1995) and Indonesia (Timmer, 1974); maize markets in Uganda (Rashid, 2004), and Celery markets in the US (Sexton et al., 1991). However, there is no similar study carried out empirically in the context of paddy markets in Sri Lanka in particular. The purpose of this study was, therefore, to fill the existing group.

\section{Methods}

\section{Theoretical Framework}

The conventional demand - supply theory explains that the actual price of a commodity in a given market (rice in this case) at a given point of time is higher than the equilibrium price when the product is "deficit" (i.e. excess demand where the demand is greater than domestic supply) and the price of which is lower than the equilibrium when it is "surplus" (i.e. excess supply where the domestic supply is greater than the demand). Consequently, there exists an opportunity for trade between these two types of markets (i.e. from surplus to deficit regional market), and ultimately these two markets become integrated by adjusting into a single price. 
The model developed by Ravallion (1986) can be used as the theoretical base to explain the said behavior, and briefed in turn. This model assumes that a radial distribution of markets where one "Central Market" with price $\mathrm{R}$ is related to other "Regional Markets" (n) with the respective prices $\mathrm{P}$ (i.e. $\mathrm{P}_{1}, \mathrm{P}_{2} \ldots \mathrm{P}_{\mathrm{n}}$ ) as follows:

$$
\begin{aligned}
& R=f\left(P_{1 \ldots} P_{n}, X\right) \\
& P_{i}=f_{i}\left(R, X_{i}\right) \text { for } i=1, \ldots, n
\end{aligned}
$$

The term $\mathrm{X} i$ in equation (1) and (2) represents a vector of other exogenous variables that might influence price formation in market $i$, (e.g. seasonal changes, government policy). The equation (1) in particular shows that price in the central market is associated with that exists in regional markets. Equation (2) indicates that price in any regional market will have an association with the price occur in the central market simultaneously. The dynamic form of equation (2), as explored by Ravallion (1986), with lag 1 is depicted in equation (3) below:

$$
p_{t}=\sum_{j=1}^{l} a_{j} P_{t-j}+\sum_{j=0}^{l} b_{j} R_{t-j}+c X_{t}+e_{t}
$$

Based on Timmer (1986), we can expand the above model as shown below:

$$
P_{t}=d_{0+}\left(1+d_{0}\right) P_{t-1}+d_{2}\left(R_{t}-R_{t-1}\right)+\left(d_{3}-d_{1}\right) R_{t-1}+d_{4} X_{i t+} e_{i t}
$$

Where, $P_{t}$ and $R_{t}$ are the logarithm of the regional market price and the central market price for month $t$, respectively; $\mathrm{X}_{i}$ is a matrix of exogenous variables; $\mathrm{d}_{i}$ are parameter estimates, and $\mathrm{e}_{\mathrm{it}}$ is the random error. With the introduction of "one lag" to the model and excluding X variables, one can derive "Index of Market Connectedness" (IMC), which is the ratio of the Regional Market Coefficient $\left(1+d_{0}\right)$ to the Central Market Coefficient $\left(d_{3}-\right.$ $\mathrm{d}_{1}$ ) (see, Timmer, 1987 for details):

$$
\text { IMC }=\left(1+d_{0}\right) /\left(d_{3}-d_{1}\right)
$$

IMC illustrates the contribution of the regional market and the central market past prices on current regional market prices. It can be used to 
evaluate the level of integration between the central and regional markets in the short run. If the IMC value falls below 1, it indicates that these two markets showing "Short Run Market Integration" (SRMI). The value of the coefficient $\mathrm{d}_{2}$ (see, equation 4 ) is a measure of the degree to which the price change in the central market is transmitted to the regional market. This parameter measures "Long Run Market Integration" (LRMI) and its value is expected to be equal or close to 1 . The difference between these two indicators is that $d_{2}$ shows the percentage of the price change in the central market is transmitted to the regional market price, whereas IMC indicates the relative percentages of the current regional price that are originating from regional market and central market past prices.

\section{Data Collection and Analysis}

Monthly retail prices of rice from January 1996 to December 2003 (i.e. 96 months) for six different markets, including: (1) Colombo (COL); (2) Kurunegala (KUR), (3) Polonnaruwa (POL), (4) Kandy (KAN), (5) NuwaraEliya (NUW), and (6) Anuradhapura (ANU) were used for the analysis, and certain districts, for example Ampara and Batticoloa were excluded from the analysis as there are no valid and reliable time series data. All the prices were deflated using the Consumer Price Index (CPI) to eliminate the effect of inflation. Amongst these markets, the first three (COL, KAN, NUW) were considered to be potentially deficit paddy markets as their per capita availability of paddy was far below that of the national average (i.e. <98 $\mathrm{kg} /$ person/year). The other three (KUR, POL, ANU) were termed as surplus paddy markets as their values (i.e. $>200 \mathrm{~kg} /$ person/year) are well above the national average.

In this analysis, the Colombo market was assumed to be the Central Market due to a number of reasons, Viz., (1) it is the largest urban centre in the country where the rice trading is taken place with the highest intensity both at the wholesale/retail level; (2) it has the highest population in the country with comparatively low paddy production that makes its per capita availability of rice to the lowest in Sri Lanka (i.e. < $10 \mathrm{~kg} /$ person/year); (3) it retains the highest per capita income compared to all other districts in Sri Lanka, and (4) it has the largest commercial harbor in the country that carries out import and export of rice predominately. The statement (2) above indicates that Colombo market is theoretically food insecure, while (3) and (4), together, highlight that it has an ability to overcome such insecurities 
within a relatively short period of time compared to its counterparts, because of higher per capita purchasing power and the ability to engage in international trade straightforwardly.

Both descriptive and inferential statistics were used to analyze data, including mean prices, Coefficient of Variations (CV) and Correlation Coefficients. The coefficients of parameters in the Ravallion model were estimated for each regional market using Least Square Techniques (Maddala, 1992), and that were used to derive the integration coefficients.

\section{Results and Discussion}

\section{Behaviour of Mean Paddy Prices}

The outcome of the analysis suggests that during January 1996 to December 2003, the highest mean price of rice was observed in the Colombo market (Rs. 1.75 per $\mathrm{Kg}$; SD = 0.199) followed by the Kandy market (Rs. 1.74 per $\mathrm{Kg} ; \mathrm{SD}=0.223$ ). The lowest mean price was reported in the Anuradhapura market (Rs. 1.63 per Kg; SD = 0.222) (Figure 5).

Economic theory predicts that for a pair of trading markets that are in equilibrium, difference between the prices in these markets (i.e. spatial price differential) is not expected to be zero, because of cost of transportation. However, any price difference beyond this may be resulting from disintegration of these markets due to various reasons. For this particular case, the difference between mean prices of the central and regional market is highest (Rs. 0.12) in the Colombo - Anuradhapura market followed by the Colombo - Polonnaruwa market (0.10). These suggest that mean prices are not distorted significantly amongst the set of central and regional markets considered in this analysis. 
Figure 5: Mean price of rice in the reference (COL) and regional markets

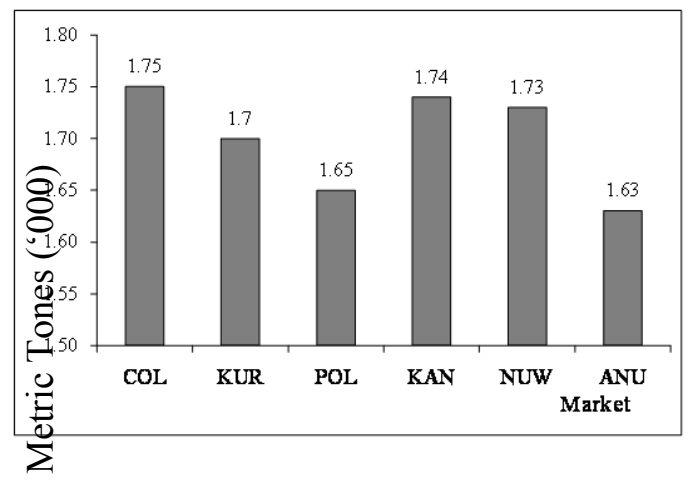

\section{Coefficient of Variation}

The Coefficient of Variation (CV) estimated for the prices prevail in each market is an indication of the extent to which a market is integrated over time. The larger values of CV indicate loosely integrated market overtime or a market with fewer opportunities to integrate for future because of high price risk. The results suggest that $\mathrm{CV}$ value of all the markets were closer to 0.1 with the highest value in the Anuradhapura market (0.137) and the lowest in the Kurunegala market (0.108) (Figure 6).

These values suggest that prices in these markets were not much volatile due to reasons that are internal to the market (e.g. increase of regional prices due to shortages in supply). The results also show that the distance between two regional markets has a positive relationship with the spatial price difference, i.e. the price difference is higher as the distance increases. 
Figure 6: $\quad$ Values of Coefficient of Variation

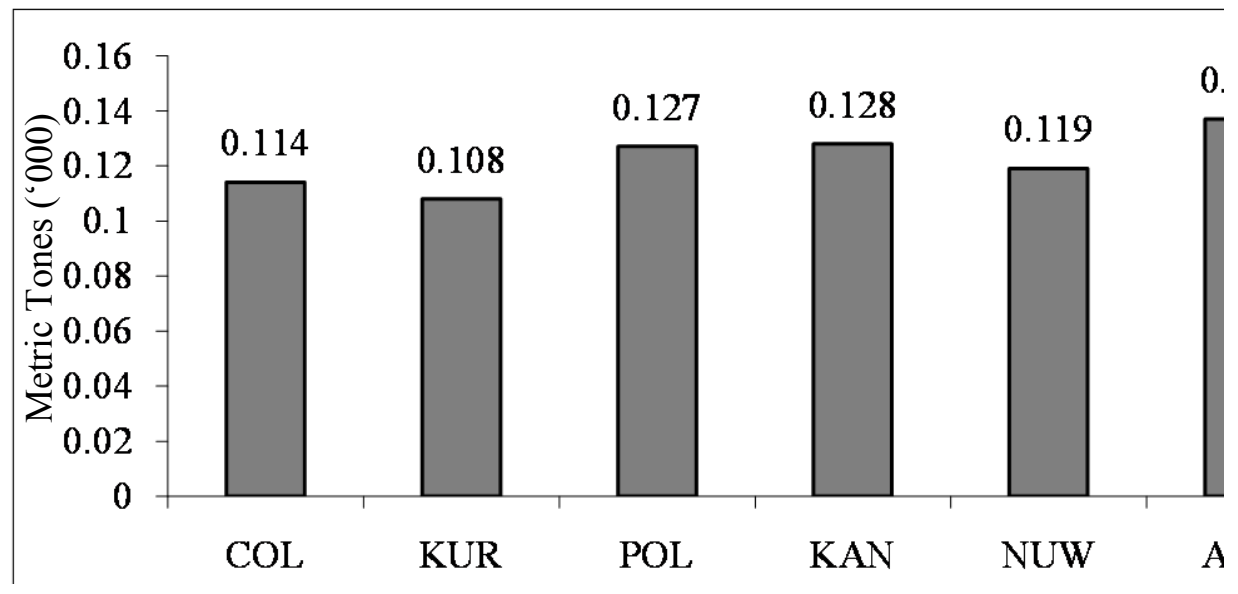

\section{Correlation Analysis}

The results from the correlation analysis revealed that there was a higher and significant (Prob. $=0.01$ ) correlation with respect to prices among these markets, and in all cases it was above 0.9 including the average correlation coefficient. This also suggests that these markets were highly integrated with each other during this period (Table 1). 
Table 1: $\quad$ Real price correlation matrix:

\begin{tabular}{lcccccc}
\hline & COL & KUR & POL & KAN & NUW & ANU \\
\hline COL & 1.000 & & & & & \\
KUR & 0.986 & 1.000 & & & & \\
POL & 0.984 & 0.987 & 1.000 & & & \\
KAN & 0.975 & 0.980 & 0.981 & 1.000 & & \\
NUW & 0.978 & 0.976 & 0.978 & 0.966 & 1.000 & \\
ANU & 0.989 & 0.991 & 0.988 & 0.981 & 0.970 & 1.000 \\
AVE & 0.983 & 0.982 & 0.983 & 0.976 & 0.973 & 0.981 \\
\hline
\end{tabular}

\section{Status of Short Run and Long Run Market Integration}

The coefficients estimated for equation (4) have been used to derive the values for the Short Run (SRMI) and Long Run (LRMI) market integration (i.e. IMC and d2), and are illustrated in Figure 7.

Figure 7: $\quad$ Short run and Long run indicator values

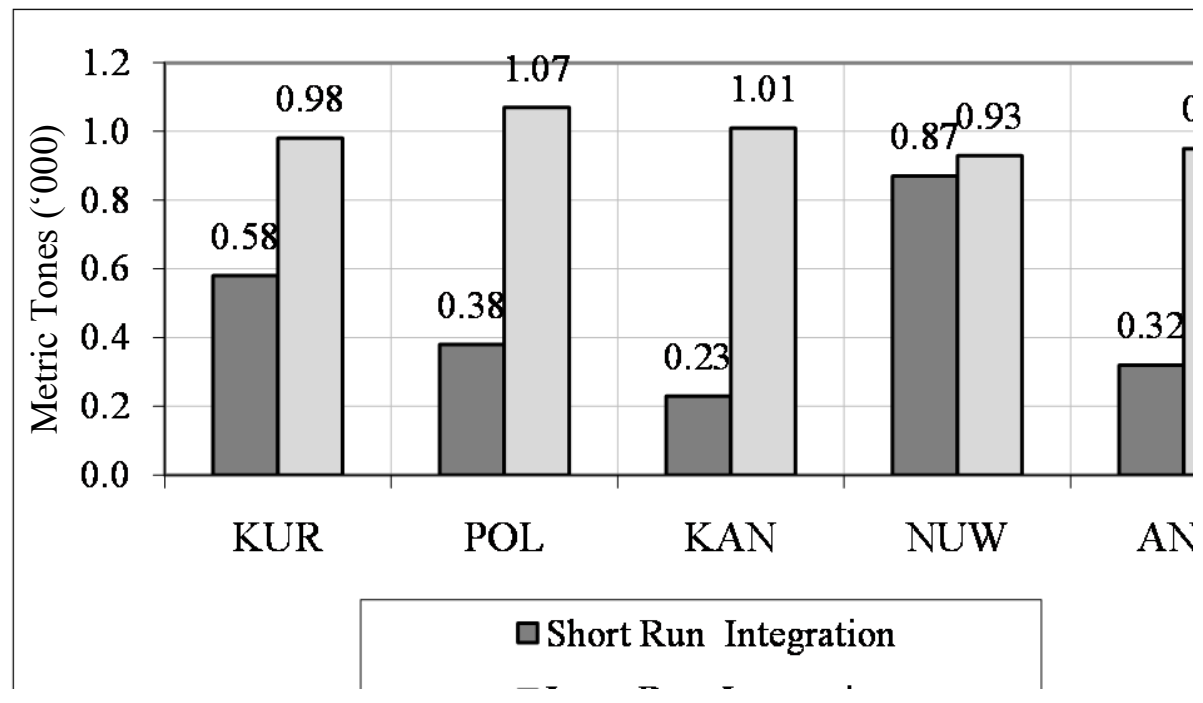


The values less than 1 for IMC for the set of central and regional markets indicate the existence of short run integration between these markets and the Colombo central market. It shows that SRMI was the highest in the Colombo - Kandy market channel (0.23) and the lowest (0.87) in the Colombo - Nuwara-Eliya market channel.

With regard to the integration of market in the long run, the LRMI of the six market channels considered were close to 1 , with the highest value in the Colombo - Pollonnaruwa market (1.07) and the lowest in the Colombo Nuwara-Eliya (0.93). The slight deviation of the lowest and highest values of LRMI (0.07) from the required value of 1 implies that these markets are integrated in the long run satisfactorily. It was also revealed that the magnitude of the LRMI declines, in general, as a regional market was away from the central market (i.e. with the distance between two markets), except in the case of Nuwara-Eliya where it was recorded to be the highest (Figure 8).

Figure 8: $\quad$ Variation of the SRMI and LMRI with the distance:

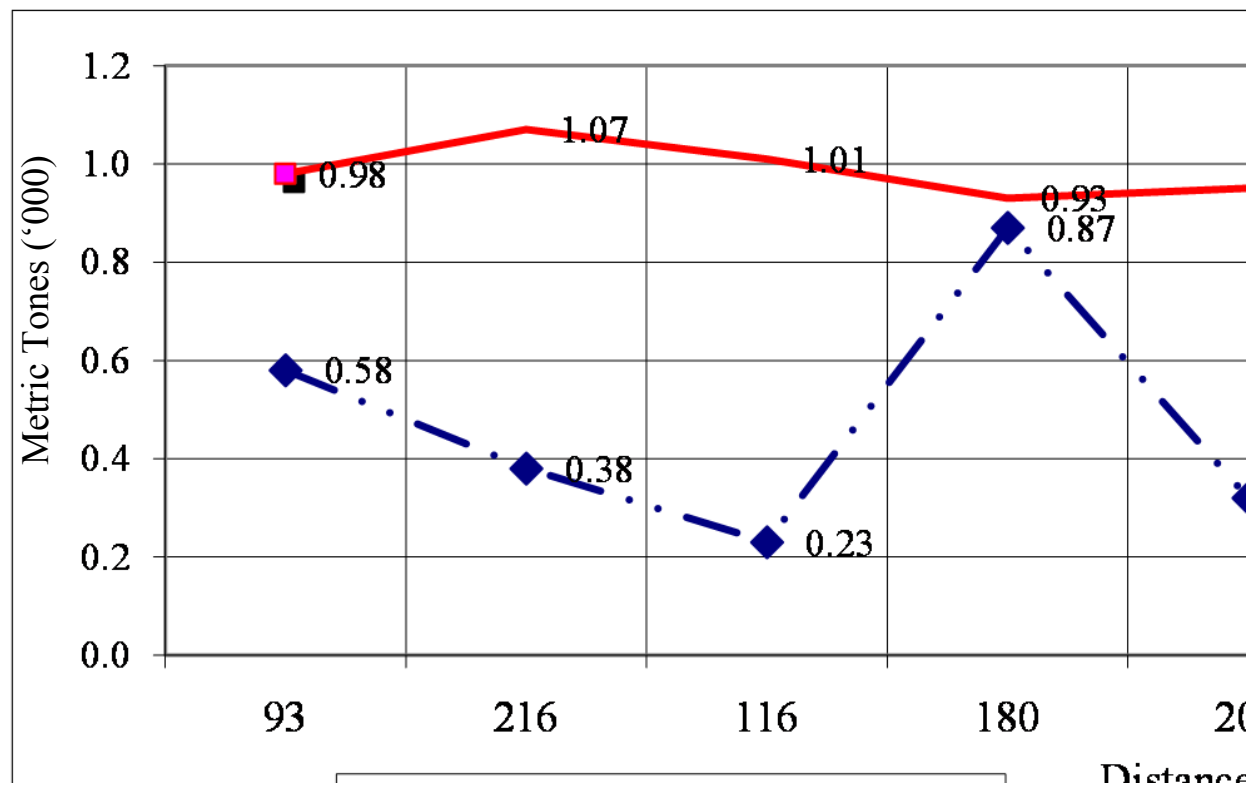


The low integration in the Colombo - Nuwara-Eliya market, both in the short run and the long run, may be a result of difficulties associated with distribution of commodities, due to poorly maintained road network that runs through large hills and up county tea plantations. Also, the unpredictable weather conditions (frequent raining, hails and mist) and catastrophic events (earth slides and water logging) have impact very frequently on transportation as well as dissemination of valid and reliable market information to prospective traders on time.

\section{Conclusions and Policy Implications}

This study examined empirically the spatial integration of markets for rice in Sri Lanka, i.e. impact of price originated in a central market on the price formation of set of regional markets, using the special case of paddy and rice trading system in the country. There were three districts that produce paddy in large quantities (i.e. above the per capita national average), namely Kurunegala, Anuradhapura, and Pollonnaruwa and three others that, in general, produce relatively low quantities (i.e. below the per capita national average), namely: Colombo, Kandy, and Nuwara-Eliya used to examine this problem where the Colombo market was considered as the focal point of price formation.

The results suggest that prices in these markets were highly integrated, irrespective of whether they are surplus or deficit markets both in the short run and long run perspective and geographical location. In the short run, the Colombo - Nuwara-Eliya and Colombo - Kandy market show the lowest and highest integration, respectively. The Colombo - Nuwara-Eliya and the Colombo - Polonnaruwa market, respectively, were integrated with the lowest and highest intensity in the long run. The results from the Correlation Analysis and Coefficient of Variation suggest that these individual markets, within themselves and over the time, were also very much integrated.

The outcome of the analysis has some implications for food and agriculture related policy. The integration of markets in this industry means that information flow and the infrastructure is reasonably in place, and it can be toughened by strengthening the institutions set up for these purposes. More interestingly, it proves that the government can intervene effectively at the 
Central Markets, directly and/or indirectly by way of credible threats for food imports and export bans etc., to adjust the prices in regional markets.

\section{References}

Central Bank of Sri Lanka (2005). Annual Report. Central Bank of Sri Lanka, Sri Lanka.

Goletti, F., R. Ahmed and N. Farid (1995). Structural Determinants of Rice Market Integration: The Case of Rice Markets in Bangladesh. The Developing Economics, 33(2): 517-546.

Luts, C., C. Paagman and L.T.D. Hai. (2006). Rice Market Integration in the Mekong River Delta. Economics of Transition, 14(3): 517-546.

Maddla, G.S. (1986). Introduction to Econometrics". $2^{\text {nd }}$ Edition. New York: McMillin Publishing House.

Rashid, S., (2004). Spatial Integration of Maize Markets in Post-liberalized Uganda. Journal of African Economics, 13(1): 102-133.

Ravallion, M. (1986). Testing Market Integration. American Journals for Agriculture Economics, 1: 102-108.

Sexton, R.J., C.L. Kling and H.F. Carman (1991). Market Integration, Efficiency of Arbitrage, and Imperfect Competition: Methodology and Application to US Celery. American Journals for Agriculture Economics, 45: 369-380.

Timmer, P.C. (1986). Getting Prices Right - The Scope and Limits of Agricultural Price Policy. Ithaca, NY: Cornell University Press.

Timmer, P.C. (1974). A Model of Rice Marketing Margins in Indonesia. Food Research Institute Studies, 12(2): 145-167. 